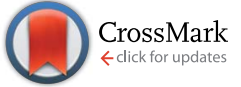

Cite this: RSC Adv., 2017, 7, 4297

Received 22nd November 2016 Accepted 27th December 2016

DOI: 10.1039/c6ra27127h

www.rsc.org/advances

\section{Removal of $\mathrm{NaCl}$ from saltwater solutions using micro/mesoporous carbon sheets derived from watermelon peel via deionization capacitors $\uparrow$}

\author{
Shanshan Zhao, Tingting Yan, Zhuo Wang, Jianping Zhang, Liyi Shi \\ and Dengsong Zhang*
}

Micro/mesoporous carbon sheets with high specific surface area (up to $2360 \mathrm{~m}^{2} \mathrm{~g}^{-1}$ ) were successfully prepared by using watermelon peel as a carbon source through a simple activation method and were originally developed as highly efficient electrodes for flow-through deionization capacitors to remove $\mathrm{NaCl}$ from saltwater solutions. The carbon source is low-cost and the approach is very simple, effective and environmentally-friendly. Owing to the micro/mesoporous structure and high specific area, the obtained electrode presents a superior wettability and good electrochemical performance. In the deionization experiments, the electrodes show a high deionization capacity of $17.38 \mathrm{mg} \mathrm{g}^{-1}$ at $1.2 \mathrm{~V}$ in a $500 \mathrm{mg} \mathrm{L}^{-1} \mathrm{NaCl}$ solution. Besides, the electrodes possess a high deionization rate at $0.8-1.4 \mathrm{~V}$ in 100-500 $\mathrm{mg} \mathrm{L}^{-1} \mathrm{NaCl}$ solutions. The electrodes also present a good regeneration behavior. The good performance makes the electrodes promising candidates for flow-through deionization capacitors. We also hope that the micro/mesoporous carbon sheets can be applied to other areas.

\section{Introduction}

The freshwater shortage has become a serious problem limiting human development, ${ }^{1,2}$ therefore finding effective methods to produce freshwater is quite urgent. Seawater desalination attracts great interest. Membranes, reverse osmosis and electrodialysis are the most used methods. However, these methods always suffer from such disadvantages as excessive energy-consumption, high cost and secondary pollution. ${ }^{3}$ Capacitive deionization is an emerging technology for seawater and brackish water desalination using a flow-through deionization capacitor (FTDC). The FTDC is based on the principle of electric double layer capacitors (EDLCs). When a cell voltage is added, the electrodes would be charged, and the ions would move towards the electrodes and then be adsorbed on the electric double layer (EDL) formed between the electrode interface and the solution. After the cell voltage is removed, the ions can be desorbed immediately. ${ }^{4-6}$ The

Research Center of Nano Science and Technology, Shanghai University, Shanghai 200444, China. E-mail: dszhang@shu.edu.cn

$\dagger$ Electronic supplementary information (ESI) available: Schematic of the flow-through electrode setup, SEM images of the freeze dried watermelon peel and carbonized watermelon peel (before HF etching), XRD pattern of the carbonized watermelon peel (before HF etching), XPS spectra of MMC-A and MMC, $C V$ curves of the electrodes at $1 \mathrm{mV} \mathrm{s}^{-1}$ in $500 \mathrm{mg} \mathrm{L}^{-1} \mathrm{NaCl}$ solution, deionization curves of the MMC electrodes in $100-500 \mathrm{mg} \mathrm{L}^{-1} \mathrm{NaCl}$ solutions, deionization curve and plot of SAC of the MMC-A electrodes in $1000 \mathrm{mg} \mathrm{L}^{-1}$ $\mathrm{NaCl}$ solution at $1.2 \mathrm{~V}$, regeneration curve of the MMC-A electrodes in a $150 \mathrm{mg}$ $\mathrm{L}^{-1} \mathrm{NaCl}$ solution at $1.2 \mathrm{~V}$, comparison of SAC of various carbon electrode materials from the literature. See DOI: $10.1039 / \mathrm{c} 6 \mathrm{ra} 27127 \mathrm{~h}$
FTDC has such advantages as low energy-consumption, high efficiency and environmental friendliness., ${ }^{7,8}$

The properties of electrode material play a vital role in the FTDC. ${ }^{9}$ Activated carbon, ${ }^{\mathbf{1 0 - 1 2}}$ carbon aerogels, ${ }^{\mathbf{1 3 - 1 5}}$ graphene, ${ }^{16,17}$ carbon nanotubes, ${ }^{18,19}$ mesoporous carbon, ${ }^{20,21}$ carbon nanofibers ${ }^{22-24}$ and their composites ${ }^{25-28}$ are widely used as FTDC electrode materials today. Among them, activated carbons attract great interest due to low cost, high specific surface area and environmental compatibility. ${ }^{29}$ However, the pore structure of activated carbons are mainly composed of micropores, which restricts the ion diffusion and not beneficial to the deionization process. $^{30}$ Mesoporous carbons have numerous of mesopores, which would be in favor of the salt ions transporting ${ }^{31,32}$ and thus show a higher deionization capacity than activated carbon. ${ }^{20}$ Porous carbon with different pore size distribution combines the advantages of different pore structures and thus shortens the ion transport pathway, reduce the resistance and provide larger accessible surface area for salt ions. It has been demonstrated that the porous carbon materials with different pore structures have shown excellent performance in electrochemistry ${ }^{31-34}$ and also have been used as FTDC electrodes. ${ }^{35-37}$

Recently, biomass derived carbon materials are gaining increasing attention due to their advantages of easy to get, facile to prepare, low-cost, effectiveness and environmentally friendly. Up to now, some biomass materials such as soybeans, ${ }^{29}$ eggplants, ${ }^{38,39}$ leaves, ${ }^{40}$ banana peel, ${ }^{41}$ seed shells, ${ }^{42,43}$ fungi, ${ }^{44}$ seaweed $\mathbf{s}^{\mathbf{4 5 - 4 7}}$ and coffee beans ${ }^{\mathbf{4 8}}$ have been applied to prepare porous carbon and the obtained carbon materials have shown 


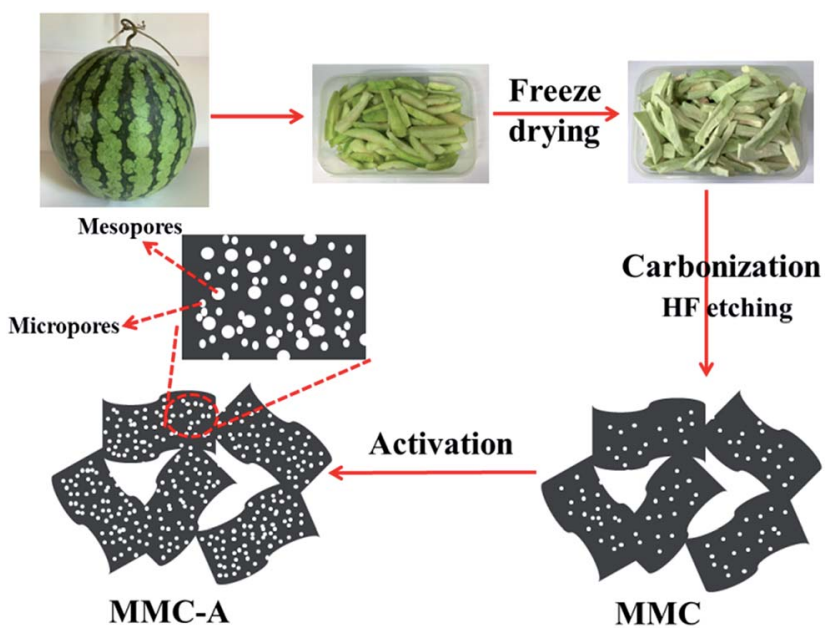

Fig. 1 Schematic illustration of preparation process of the MMC-A.

good performance in many areas such as supercapacitors, lithium batteries and oxygen reduction reaction. Watermelon is a common fruit anywhere. The peel is always been thrown away. It is interesting that carbon materials could be obtained from watermelon peel. ${ }^{\mathbf{4 9 , 5 0}}$ As far as we know, no work about watermelon peel-derived carbon as electrode materials for FTDC is reported so far.

In this work, we prepared micro/mesoporous carbon sheets (MMC-A) with high specific surface area using watermelon peels as carbon source through a simple activation approach and originally developed as highly efficient electrodes for flowthrough deionization capacitors to remove $\mathrm{NaCl}$ from saltwater solutions. Fig. 1 illustrates the preparation of the MMC-A. The watermelon peel was first freeze dried and then carbonized. After etching with HF in order to remove the impurity, the micro/mesoporous carbon (MMC) was obtained. Finally, a simple $\mathrm{KHCO}_{3}$ activation process was employed to obtain the MMC-A. The $\mathrm{KHCO}_{3}$ can decompose when heated and generate gases including $\mathrm{CO}_{2}$ and $\mathrm{CO}$, which could enlarge the size of a portion micropores and render them become mesopores. The activator and gases can also react with carbon and these reactions contribute to the formation of another portion of mesopores and micropores. As a result, numerous mesopores, micropores and high specific surface area are all obtained. These characteristics provide the MMC-A larger accessible surface area, more convenient transporting pathways and good wettability. The MMC-A electrode has a good electrochemical performance. The MMC-A electrodes also exhibits a high deionization capacity, fast deionization rate and good regeneration behavior.

\section{Experimental section}

\subsection{Materials}

All chemicals were purchased by Sinopharm Chemical Reagent Co., Ltd. The watermelon was purchased from Wal-Mart supermarket (Qilian Road, Shanghai, P. R. China).

\subsection{Preparation}

Watermelon peels were first cut into chips shape using a fruit knife and then freeze-dried for dozens hours. The dried peel was then calcined at $800{ }^{\circ} \mathrm{C}$ for $3 \mathrm{~h}\left(5^{\circ} \mathrm{C} \mathrm{min}{ }^{-1}\right)$. The obtained black sample was ground into powder and washed by $10 \%$ of $\mathrm{HF}$ in order to remove the impurity. After washed by deionized water and dried, the prepared sample was mixed with $\mathrm{KHCO}_{3}$ (the ratio of carbon to $\mathrm{KHCO}_{3}$ is $1: 8$ ) in deionized water and the mixture was evaporate to dryness at $60{ }^{\circ} \mathrm{C}$. Afterwards, the dried mixture was heated at 600,700 and $800{ }^{\circ} \mathrm{C}$ for $3 \mathrm{~h}\left(5^{\circ} \mathrm{C}\right.$ $\left.\min ^{-1}\right)$. The resulting sample was then washed using a $2 \mathrm{~mol}$ $\mathrm{L}^{-1} \mathrm{HCl}$ solution so as to remove the inorganic impurity. Finally, the black samples were obtained after drying at $60{ }^{\circ} \mathrm{C}$. The obtained black carbon materials were named as MMC-A- $x$, where $x$ is the calcination temperature. For comparison, the MMC was prepared by direct calcining the watermelon peels and etching with $\mathrm{HF}$ without the activation process.

\subsection{Characterization}

The $\mathrm{N}_{2}$ adsorption-desorption tests were carried out on Autosorb-IQ2 (Quantachrome Corporation). The BET method was applied to calculate the specific surface area. The pore size distribution was obtained from the slit/cylinder pores QSDFT adsorption model. The micropore surface area $\left(S_{\text {micro }}\right)$ and the external surface area $\left(S_{\text {ext }}\right)$ were obtained from $t$-plot analysis. The samples were then characterized by using SEM on JEOL JEM-6700F, TEM on JEOL JEM-2010F and XRD on Rigaku D/ MAX-RB X-ray diffractometer. The wettability of the electrodes was measured using dynamic contact angle analysis on KrüssDSA100. X-ray photoelectron spectroscopy (XPS) was tested on a Perkin-Elmer PHI 5000C ESCA system equipped with a dual $\mathrm{X}$-ray source, using the $\mathrm{MgK} \alpha(1253.6 \mathrm{eV})$ anode and a hemispherical energy analyzer. The $C V$ and EIS tests were carried out on CHI 660D (Chenhua Co., Ltd., Shanghai). The GC analysis was measured on CT2001A (Land Electronic, Wuhan). The three-electrode system was applied during all the process, in which the MMC-A or MMC electrode was used as working electrode, a piece of graphite was used as counter electrode and a saturated calomel electrode was used as reference electrode respectively. The concentration of the $\mathrm{NaCl}$ solution is $0.5 \mathrm{M}$. The specific capacitances were obtained from the equation: ${ }^{\mathbf{5 1 , 5 2}}$

$$
C=\left(\int I \mathrm{~d} V\right) / 2 v \Delta V m
$$

where $C$ is the specific capacitance, $I$ is the response current density, $\mathrm{d} V$ is the potential window, $v$ is the sweep rates, and $m$ is the mass of the electrodes.

\subsection{Deionization experiments}

The electrodes consist of $80 \mathrm{wt} \%$ of MMC-A or MMC, $10 \mathrm{wt} \%$ of conductive carbon black and $10 \mathrm{wt} \%$ of binder (PTFE). The obtained slurries were pressed on the graphite paper. The obtained electrodes were then dried at $120{ }^{\circ} \mathrm{C}$ overnight. The mass of the electrodes were $0.2 \mathrm{~g}$. The size of the electrodes were $5 \mathrm{~cm}$ $\times 5 \mathrm{~cm}$. The thickness of the electrodes was $0.2 \mathrm{~mm}$. Finally the electrodes were equipped into the deionization device with 
a continuously recycling system to test the deionization performance (Fig. S1†). The FTDC device consists of two electrodes, which are separated by a piece of insulating grid spacer. With the help of the peristaltic pump, the $\mathrm{NaCl}$ solution can flow through the device circularly. The device was equipped with a conductivity meter, which can measure the conductivity value of $\mathrm{NaCl}$ solution in real-time. The volume of $\mathrm{NaCl}$ solution is $30 \mathrm{~mL}$. The flow rate of the $\mathrm{NaCl}$ solutions was $40 \mathrm{~mL} \mathrm{~min}{ }^{-1}$. The concentration of the $\mathrm{NaCl}$ solutions was $100-500 \mathrm{mg} \mathrm{L}^{-1}$. The applied voltages were 0.8-1.4 V.

The salt adsorption capacity (SAC) of the FTDC electrodes were obtained from the formula (2): ${ }^{25,53}$

$$
\mathrm{SAC}=\left(C_{0}-C\right) V / m
$$

in which $C_{0}$ and $C$ are the initial and final concentrations, respectively. $V$ is the volume of the solution. $m(\mathrm{~g})$ is the total mass of the active material.

The charge efficiency $(\Lambda)$ is obtained from the formula (3): ${ }^{16,54}$

$$
\Lambda=(\Gamma \times F) / \Sigma
$$

in which $\Gamma$ is the deionization capacity $\left(\mathrm{mol} \mathrm{g}^{-1}\right), F$ is the Faraday constant $\left(96485 \mathrm{C} \mathrm{mol}^{-1}\right.$ ) and $\Sigma$ (charge, $\mathrm{C} \mathrm{g}^{-1}$ ) is calculated through integrating the current.

\section{Results and discussion}

\subsection{Characteristics}

The activation temperature is a key factor that determines the specific surface area and pore size. Fig. 2a depicts the nitrogen sorption isotherms of all the samples. All the isotherms exhibit similar type that can ascribed to the mixture of type I (b) and type IV (a) with the type H4 hysteresis loops, according to the IUPAC Technical Report. ${ }^{55}$ At low relative pressure, the curves are very steep, implying the existence of micropores. ${ }^{54}$ The broad hysteresis loops appear at high relative pressure proves the existence of mesoporous structure. ${ }^{34}$ From the MMC to MMC-A, the adsorbed volume is increased notably, elucidating the enhanced specific surface area and pore volume. Fig. $2 b$ depicts the pore size distributions of all the samples. The pore size is mainly centered at the range of $\sim 0.50-33 \mathrm{~nm}$, indicating they have both micropores and mesopores. For MMC, a sharp peak appears at $0.52 \mathrm{~nm}$ indicates the MMC is micropores dominated. After activation, the intensities of peaks situated at the micropore range are much lower and at the mesopore range are stronger, indicating the increase of the mesopores. For MMC-A-800, the peaks mainly situated at $0.57,0.85$, indicating it has a large portion of micropores. From the inset in Fig. 2b, the MMC-A exhibits peaks at 2.43, 2.70, 3.01 and $3.94 \mathrm{~nm}$, which can prove that the MMC-A has mesopores. Table 1 exhibits the surface texture properties of all the samples. The MMC has the lowest specific surface area and pore volume $\left(872 \mathrm{~m}^{2} \mathrm{~g}^{-1}, 0.43\right.$ $\mathrm{cm}^{3} \mathrm{~g}^{-1}$ ). After activation, the specific surface area is increased. Moreover, with the activation temperature increased, the specific surface area and pore volume are all enhanced
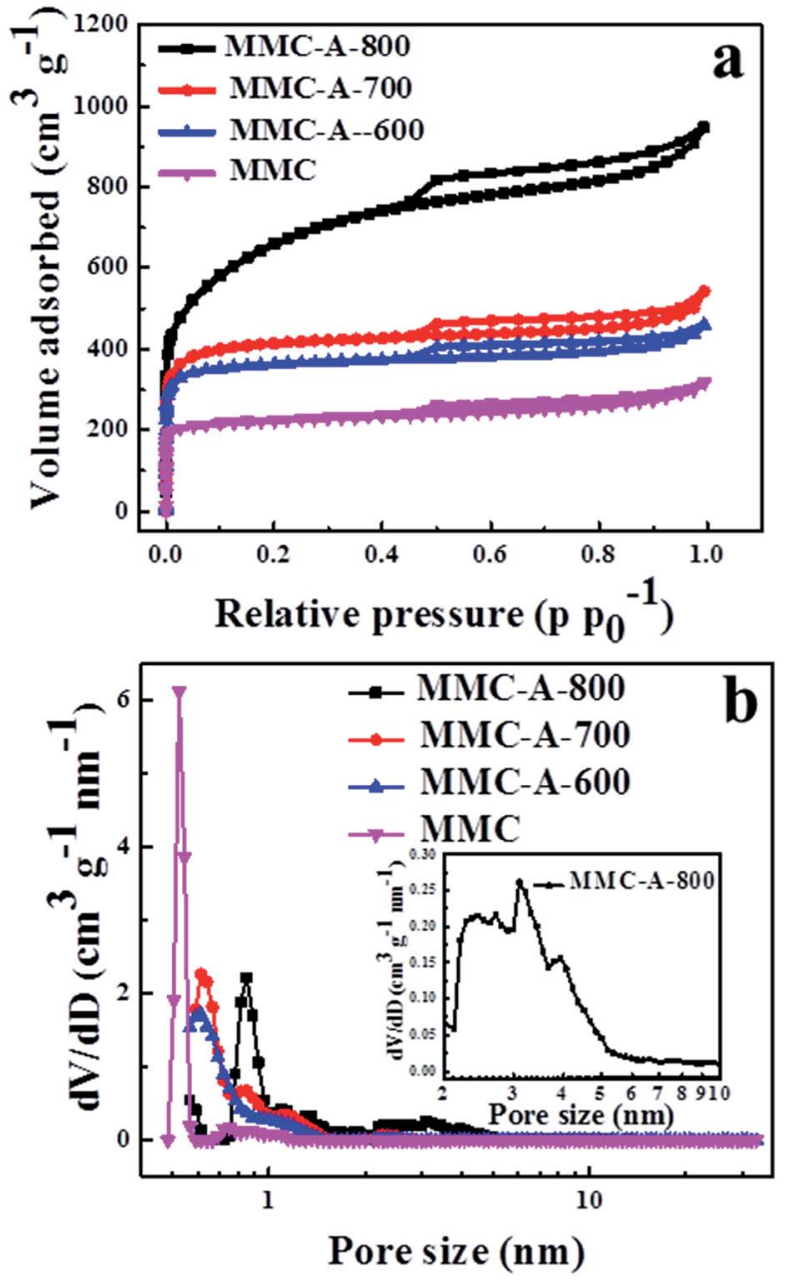

Fig. 2 (a) Nitrogen sorption isotherms and (b) pore size distributions of all the samples. The inset is the pore distribution of MMC-A-800 in the pore range of $2-10 \mathrm{~nm}$.

correspondingly. The reason is that at higher temperature, the activation process would occur more completely. The MMC-A800 has the highest specific surface area and the highest pore volume (2360 $\mathrm{m}^{2} \mathrm{~g}^{-1}$ and $\left.1.31 \mathrm{~cm}^{3} \mathrm{~g}^{-1}\right)$. It should be noted that the micropore surface area of the MMC-A-600, MMC-A-700 and MMC-A-800 are rather similar while the external surface area of the MMC-A-800 is significantly higher than that of the MMC-A600 and MMC-A-700. This is mainly because that during the activation process, a series of reactions would take place as indicated in the eqn (4)-(8). ${ }^{31,56-58}$ At about $200{ }^{\circ} \mathrm{C}, \mathrm{KHCO}_{3}$ would decompose as listed in the eqn (4). When the temperature exceeds to $400{ }^{\circ} \mathrm{C}$, the eqn of (5)-(8) would take place. ${ }^{59} \mathrm{In}$ addition, when the temperature get increased, the decomposition rate would be quicker, and this is also beneficial to enlarging the pore size. ${ }^{31}$ In consideration that the MMC-A-800 has a large amount of micropores and mesopores, we choose the MMC-A-800 as the sample to study the electrochemical and deionization performance. For convenience sake, the MMC-A800 is named as MMC-A in the following text.

$$
2 \mathrm{KHCO}_{3} \rightarrow \mathrm{K}_{2} \mathrm{CO}_{3}+\mathrm{CO}_{2}+\mathrm{H}_{2} \mathrm{O}
$$


Table 1 Surface texture properties of the samples

\begin{tabular}{|c|c|c|c|c|c|}
\hline Samples & $S_{\text {BET }}\left(\mathrm{m}^{2} \mathrm{~g}^{-1}\right)$ & $S_{\text {micro }}\left(\mathrm{m}^{2} \mathrm{~g}^{-1}\right)$ & $S_{\text {ext }}\left(\mathrm{m}^{2} \mathrm{~g}^{-1}\right)$ & $V_{\text {total }}\left(\mathrm{cm}^{3} \mathrm{~g}^{-1}\right)$ & $D_{\max }(\mathrm{nm})$ \\
\hline MMC-A-800 & 2360 & 1301 & 1059 & 1.31 & 0.85 \\
\hline MMC-A-700 & 1611 & 1313 & 298 & 0.71 & 0.61 \\
\hline MMC & 872 & 650 & 222 & 0.43 & 0.52 \\
\hline
\end{tabular}

$$
\begin{gathered}
\mathrm{K}_{2} \mathrm{CO}_{3} \rightarrow \mathrm{K}_{2} \mathrm{O}+\mathrm{CO}_{2} \\
\mathrm{~K}_{2} \mathrm{CO}_{3}+2 \mathrm{C} \rightarrow 2 \mathrm{~K}+3 \mathrm{CO} \\
\mathrm{K}_{2} \mathrm{O}+\mathrm{C} \rightarrow 2 \mathrm{~K}+\mathrm{CO} \\
\mathrm{CO}_{2}+\mathrm{C} \rightarrow 2 \mathrm{CO}
\end{gathered}
$$

The freeze-dried watermelon peel shows fold and sponge-like shape (Fig. S2a $\dagger$ ). After calcination, the obtained carbon presents a sheet-like shape before HF etching (Fig. S2b $\dagger$ ). Fig. 3 shows the SEM and TEM images of the MMC-A and MMC. From Fig. $3 \mathrm{a}$ and $\mathrm{d}$, no obvious difference can be seen from the SEM images of the MMC-A and MMC. They both exhibit sheet-like shape and the size of the sheets is about several micrometers. From Fig. $3 \mathrm{~b}$ and e we can see that both MMC-A and MMC have a large number of mesopores. Furthermore, after the activation, the resulting MMCA show richer porosity than the MMC. From Fig. $3 \mathrm{c}$ and $\mathrm{f}$, a large number of micropores can be easily identified from both MMC-A and MMC. In comparison to the MMC, the MMC-A have more micropores and mesopores. The considerable number of micropores can provide larger accessible surface area for salt ions. The mesopores can reduce the ion transport resistance.

After carbonized, the pristine carbon consists of some crystalline inorganic compounds, including $\mathrm{SiO}_{2}$ and some impurities might containing potassium, chlorine, fluorine and oxygen $^{40}$ (Fig. S3†) and thus the HF etching is necessary. Fig. 4 displays the XRD patterns of the MMC-A and MMC, which reflects the crystallinity and purity of the samples. Two broad diffraction peaks appear at a $2 \theta$ value of $\sim 23^{\circ}$ and $\sim 45^{\circ}$, which were assigned to the characteristic carbon (002) and (100) diffractions, respectively. ${ }^{60}$ Moreover, no diffractions peaks of

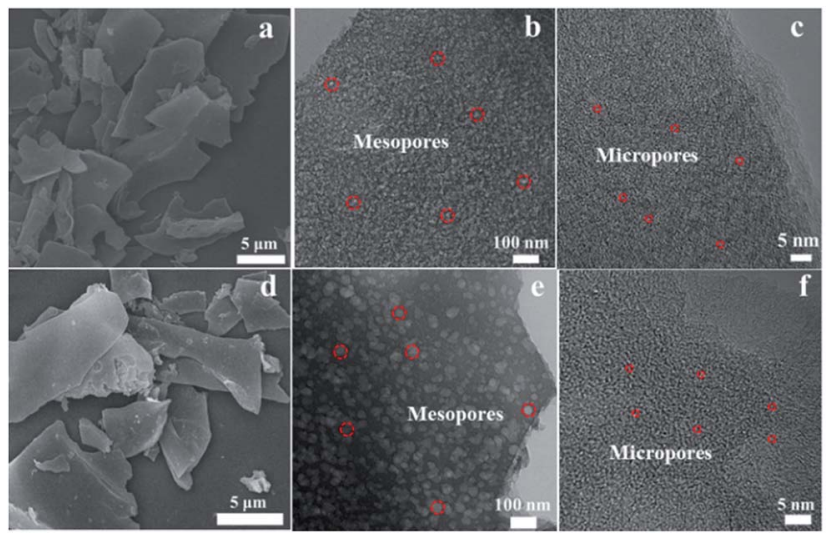

Fig. 3 SEM and TEM images of the (a-c) MMC-A and (d-f) MMC. impurity can be observed, suggesting that the samples are highly pure. The intensity of (002) peak of the MMC-A is weaker than that of MMC, indicating the MMC-A has poorer graphitization degree and more defection due to the activation process and its richer porosity. ${ }^{61}$

To study the wettability of the MMC-A and MMC electrodes, dynamic contact angle measurements were carried out and the optical micrographs are shown in Fig. 5. At the beginning of the test, the contact angle of MMC-A is $30^{\circ}$ while the MMC has a wider angle of $53^{\circ}$. As time goes on, the angle of the MMC-A electrode was decreased fast and the water droplet diffuse into the inner pores of the MMC-A electrode completely at the contact time of $1 \mathrm{~s}$. In contrast, the MMC still remains a wide angle of $29^{\circ}$. According to the XPS analysis (Fig. S4 $\dagger$ ), the content of the surface functional groups of the MMC-A and MMC is quite close, and it can be concluded that the improved wettability of the MMC-A is its richer porosity, micro/ mesoporous structure and higher specific surface area. A good wettability would lead to a sufficient contact between the electrodes and solution, which is beneficial to salt solution in filtration, and thus enhance the salt adsorption performance. ${ }^{62}$

\subsection{Electrochemical performance}

$C V$ tests were applied to evaluate potential applications of the MMC-A and MMC for FTDC. Fig. 6a shows the $C V$ profiles of the electrodes at $1 \mathrm{mV} \mathrm{s}^{-1}$ in a $0.5 \mathrm{M} \mathrm{NaCl}$ solution. Both profiles have no any oxidation and reduction peak, indicating the capacitance behavior mostly results from the ideal EDLC behavior at the salt solution-electrode interface rather than faradaic reaction. ${ }^{63}$ In addition, the curves are very symmetrical, suggesting the electrodes have a good reversible ion adsorption-desorption behavior. It also can be seen that the $C V$ curves have slight deviation from rectangular shape and the main

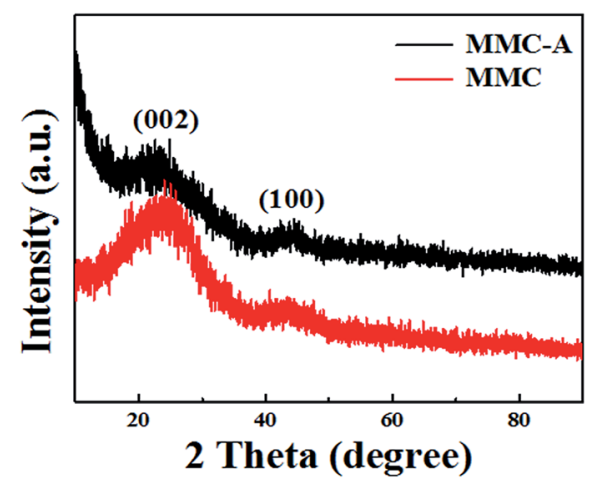

Fig. 4 XRD patterns of the MMC-A and MMC. 


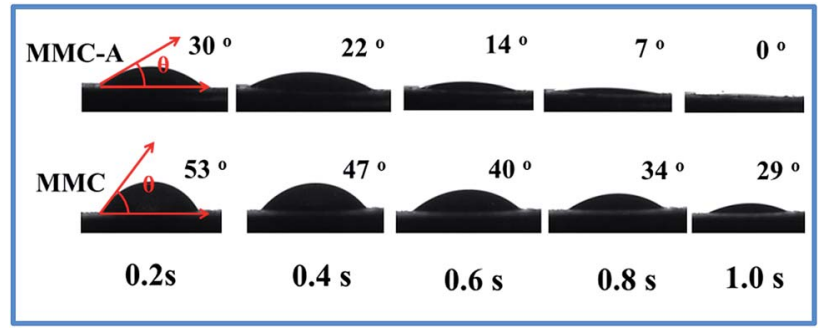

Fig. 5 Water contact angle measurement of the MMC-A and MMC electrodes.

reason for the deviation is the inherent resistivity of the salt solutions. ${ }^{64}$ The specific capacitance of the MMC-A electrode calculated from eqn (1) is $224 \mathrm{~F} \mathrm{~g}^{-1}$, which is higher than the MMC electrode $\left(176 \mathrm{~F} \mathrm{~g}^{-1}\right)$. The enhanced specific capacitance is due to the richer porosity, higher specific surface area and better wettability. Moreover, the $C V$ curves of the MMC-A and MMC electrodes at $1 \mathrm{mV} \mathrm{s}^{-1}$ in a $500 \mathrm{mg} \mathrm{L}^{-1} \mathrm{NaCl}$ solution (the same as the deionization experiment condition) have no any oxidation and reduction peak (Fig. S5 $\dagger$ ), indicating that the electrodes would not take any place Faradaic reaction during deionization process.

The Nyquist plots are also depicted. As shown in Fig. 6b, two profiles exhibit a similar shape. A semicircle and a slop line can be seen in the high frequency and low frequency, respectively. The diameter of the semicircle always indicates the polarization resistance, which reflects the charge-transfer resistance between the electrodes and the solution interface. ${ }^{65}$ Clearly, both two diameters are very small, indicating the charge transfer resistance of the electrodes is negligible. The $x$-intercept of the plots reflect the equivalent series resistance (ESR), which related to the inner resistance, including the electrodes resistance, ionic resistance of salt solution and contact resistance between the carbon materials and the current collectors. ${ }^{66}$ Generally speaking, a smaller value of ESR always indicates a smaller internal resistance. ${ }^{67}$ The ESR value of the MMC-A electrode is 0.69 , which is lower than MMC electrode and some other carbon material, ${ }^{68}$ suggesting the MMC-A possesses smaller impedance and better conductivity. The line in the low frequency indicates the capacitive behaviors of electrodes. ${ }^{69}$ The plots of the MMC-A and MMC electrodes have a similar line shape, indicating they have similar capacitive behavior. To sum up, the MMC-A electrode possesses low internal resistance and good conductivity. This is because that the MMC-A have more mesopores and micropores, and thus form a denser pore network, which can facilitate the salt ion diffusion and thus decreasing the resistance. In contrast, the MMC possess a fewer pore structures and mainly consisting of micropores, which hinder the ion diffusion and result in a greater resistance. The EIS results demonstrate that the MMC-A electrode have more easier transport pathways for salt ions and is more suitable for the FTDC.

Fig. $6 \mathrm{c}$ shows the GC profiles of the MMC-A and MMC electrodes. The profiles show a triangular shape, indicating an ideal EDLC behavior with no Faradaic reaction..$^{70,71}$ The curves show liner potential-time plots at the same time, suggesting the rapid
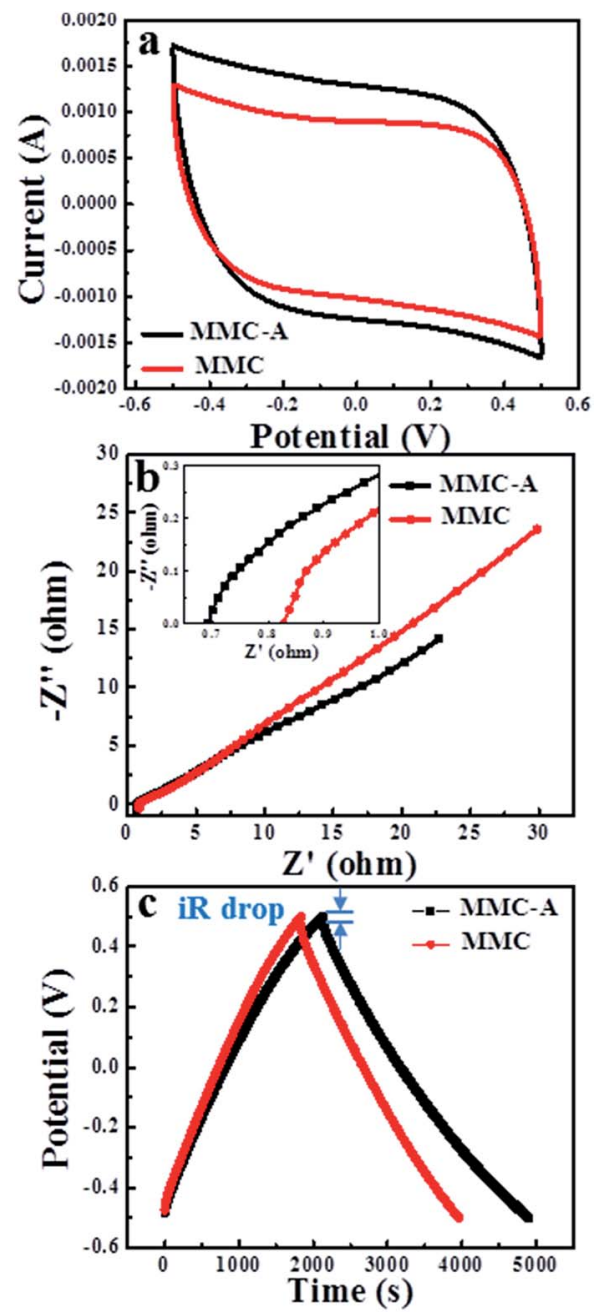

Fig. 6 (a) $C V$ curves of the electrodes at $1 \mathrm{mV} \mathrm{s}^{-1}$; (b) Nyquist profiles of the electrodes; (c) GC curves of the electrodes at $200 \mathrm{~mA} \mathrm{~g}^{-1}$. The curves were all obtained in $0.5 \mathrm{M} \mathrm{NaCl}$ solution.

$i-V$ response. ${ }^{72}$ Furthermore, the discharge time of the MMC-A electrode is longer than MMC electrode, suggesting that the MMC-A electrode has a higher specific capacitance, which corroborates the $C V$ results. However, the GC curves are not perfectly triangular and this is mainly because of the inherent resistivity of the salt solutions. ${ }^{64}$ It should be noted that the $i R$ drop can be observed at the start of discharge profiles during the GC process, which reveals the resistance of the solution, electrodes and ion diffusion..$^{37}$ The MMC-A electrode shows an $i R$ drop of $0.02 \mathrm{~V}$, which is smaller than MMC electrode (0.03 V), suggesting that the MMC-A electrode has lower resistance, which is accord with the EIS results. In brief, the pore structures of MMC-A electrode are more convenient for salt ions to transport, which forebode that the MMC-A electrodes should have good deionization performance.

\subsection{Deionization performance}

The deionization experiments of the MMC-A and MMC electrodes were carried out in a $500 \mathrm{mg} \mathrm{L}^{-1} \mathrm{NaCl}$ solution at $1.2 \mathrm{~V}$. 

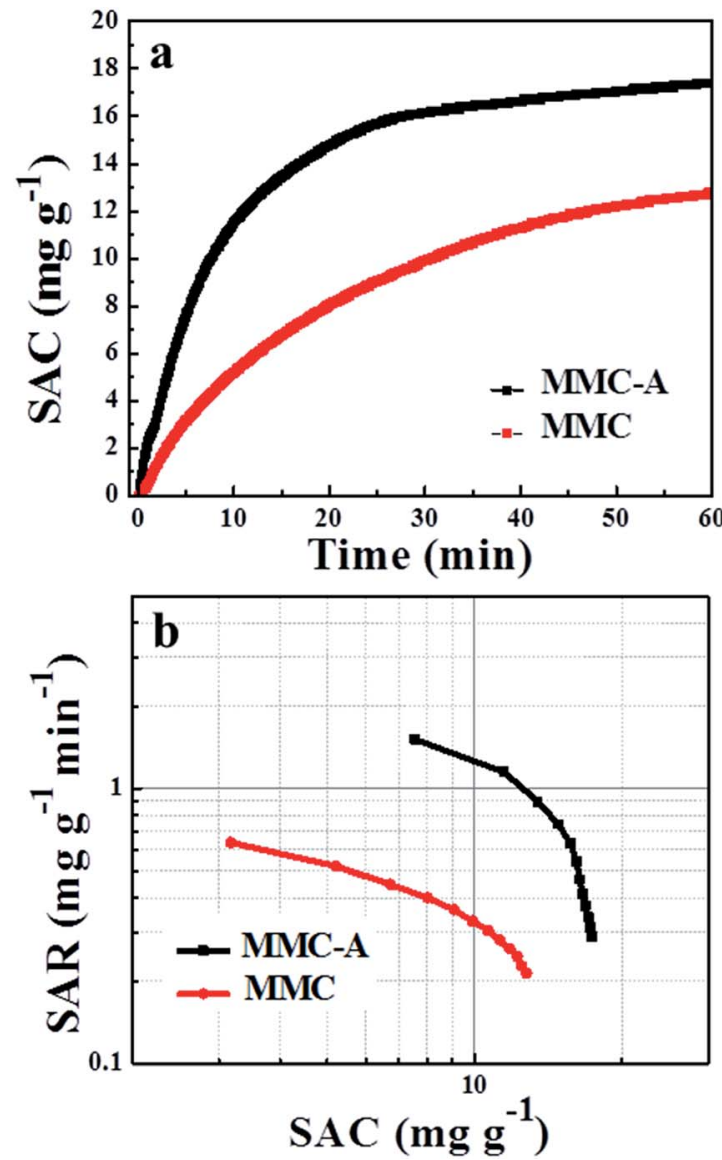

Fig. 7 (a) CDI curves and plots of SAC vs. deionization time of the electrodes; (b) Ragone plots of SAR vs. SAC for the MMC-A and MMC electrodes. The curves were obtained from $500 \mathrm{mg} \mathrm{L}^{-1} \mathrm{NaCl}$ solution at $1.2 \mathrm{~V}$.

From Fig. 7a, with the time increased within $30 \mathrm{~min}$, the conductivity of the electrodes decreases notably. Correspondingly, the SAC plot of the electrodes increase markedly. The plot of the MMC-A electrodes is more steep than MMC electrode, indicating the salt adsorption process of the MMC-A electrodes is faster. Then the plots become smooth. After $60 \mathrm{~min}$, the SAC of the MMC-A electrodes reaches to $17.38 \mathrm{mg} \mathrm{g}^{-1}$, which is better than the MMC electrodes $\left(12.77 \mathrm{mg} \mathrm{g}^{-1}\right)$. In addition, the SAC of the MMC-A electrodes is also much higher than the most FTDC electrode materials reported so far (Table S1 $\dagger$ ), indicating a good salt adsorption performance of the MMC-A electrodes. Salt adsorption rate (SAR) is also very crucial to the electrodes. Ragone plots of SAR $v s$. SAC for the electrodes was also depicted, which gives a visual representation of the deionization performance. ${ }^{8,73}$ As presented in Fig. 7b, the plot of MMC-A electrodes is in the righter and upper region, indicating the MMC-A electrodes have a higher SAC and faster SAR. At each concentration, the MMC-A electrodes possess a higher SAC and faster SAR than MMC electrodes (Fig. S6a and $\mathrm{b}_{\dagger} \dagger$ ). To each curve, with the process of the deionization, the SAC becomes higher and the SAR becomes lower. The reason is that with the deionization process goes on, the accessible surface area for salt ions become smaller and smaller. Meanwhile, the ions adsorbed into the

EDLC would generate a stronger electrostatic repulsion, which is also not in favor of the deionization. As a result, the SAC remains increasing while the SAR decreases in all the deionization process. In addition, the MMC-A electrodes also presents a good deionization performance in a high $\mathrm{NaCl}$ concentration of $1000 \mathrm{mg} \mathrm{L}^{-1}$ (Fig. S7 $\dagger$ ). The high deionization capacity and fast deionization rate of the MMC-A electrodes can be explained by the following reasons. The MMC-A possess more pores consisting of meso- and micropores. The mesopores can decrease the resistance of the salt ions in transporting process through the porous carbon, and the micropores can provide larger accessible surface area for ions. In addition, the MMC-A have a superior wettability resulting from the higher porosity and hierarchical porous structure, which lead to a sufficient contact between the electrodes and solution and makes the salt ions transporting more quickly and sufficiently.

To investigate the impact of the cell voltage on the deionization process, the voltages of $0.8-1.4 \mathrm{~V}$ were used to carry out the deionization experiments in a $100 \mathrm{mg} \mathrm{L}^{-1} \mathrm{NaCl}$ solution. As shown in Fig. 8a, once the cell voltage was applied, the SAC increases dramatically. At higher voltages, the SAC increase more quickly. From $0.8 \mathrm{~V}$ to $1.4 \mathrm{~V}$, the SAC increased from $5.84 \mathrm{mg} \mathrm{g}^{-1}$ to $13.56 \mathrm{mg} \mathrm{g}^{-1}$, indicating a higher cell voltage is in favor of enhancing the deionization capacity. It is also can be seen that the slope of the curve increase with the increase of the cell voltage, indicating the increases of SAR. These results are also can be seen from Fig. 8b, which depicts the Ragone plots of SAR vs. SAC at different cell voltages. With the cell voltage increased, the plot turns righter and upper, indicating a higher SAC and faster SAR. As we know, when the cell voltage increased, the electrostatic forces would be stronger and the EDLC would form more sufficiently and thus would be thicker. As a result, the SAC would be increased and the SAR would be faster. ${ }^{25,73}$ When the

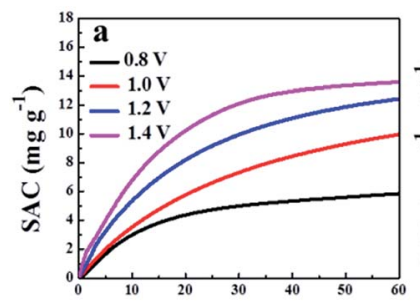

Time (min)

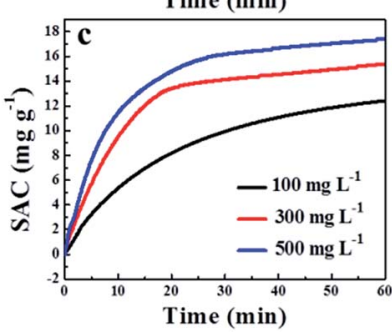

Fig. 8 (a) Plots of SAC vs. deionization time and (b) Ragone plots of SAR vs. SAC for the MMC-A electrodes at $0.8-1.4 \mathrm{~V}$ in a $100 \mathrm{mg} \mathrm{L}^{-1}$ $\mathrm{NaCl}$ solution; (c) plots of SAC vs. deionization time and (d) Ragone plots of SAR vs. SAC for the MMC-A electrodes in 100-500 $\mathrm{mg} \mathrm{L}^{-1}$ $\mathrm{NaCl}$ solutions at $1.2 \mathrm{~V}$. 
cell voltage increased, the SAC vs. SAR change less, this is because the carbon material has nearly approached the capacity limit.

The deionization performance of the MMC-A electrodes in 100-500 $\mathrm{mg} \mathrm{L}^{-1} \mathrm{NaCl}$ solutions at $1.2 \mathrm{~V}$ were also evaluated. As shown in Fig. 8c, from $100 \mathrm{mg} \mathrm{\textrm {L } ^ { - 1 }}$ to $500 \mathrm{mg} \mathrm{L}^{-1}$, the SAC increases from $12.43 \mathrm{mg} \mathrm{g}^{-1}$ to $17.38 \mathrm{mg} \mathrm{g}^{-1}$. In addition, the slop of the curves also increases, indicating the increase of the SAR. Fig. 8d displays the Ragone plots of SAR vs. SAC of the MMC-A electrodes in 100-500 $\mathrm{mg} \mathrm{L}^{-1} \mathrm{NaCl}$ solutions. Obviously, when the concentration of $\mathrm{NaCl}$ solution increases, the plot shift to righter and upper, indicating a higher SAC and faster SAR. The higher SAC is due to that when the concentration increases, the formation of the EDLC would be more effortless. The faster SAR can be explained that with the increase of the $\mathrm{NaCl}$ concentration, the conductivity would increase correspondingly, and the transport of ions would be more rapid. ${ }^{73,74}$ When the concentration of $\mathrm{NaCl}$ solution increased, the SAC vs. SAR change less, this is mainly due to that the electrodes have nearly approached the capacity limit.

The charge efficiency reflects the ratio of adsorbed salt over charge. ${ }^{8,75}$ Fig. 9a shows the current transient during the deionization process in a $100 \mathrm{mg} \mathrm{L}^{-1} \mathrm{NaCl}$ solution at $1.2 \mathrm{~V}$. The charge efficiencies of the MMC-A and MMC electrodes are
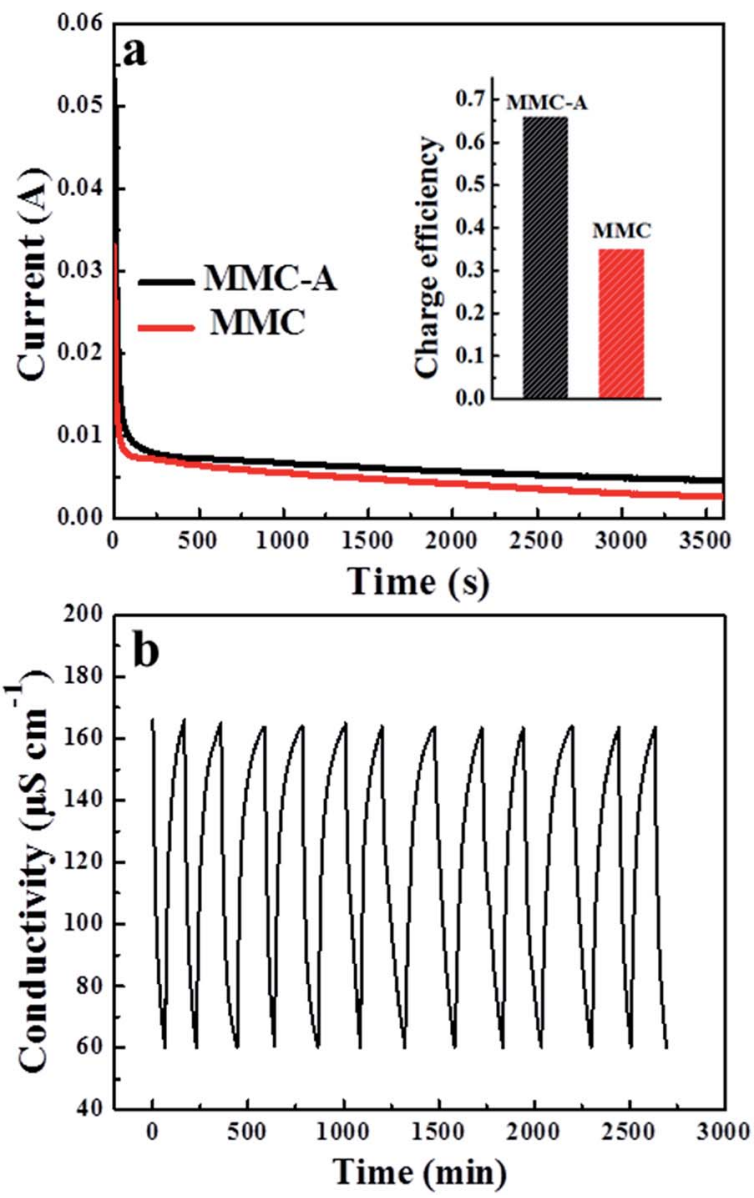

Fig. 9 (a) Current transient curves and charge efficiency for the electrodes in a $100 \mathrm{mg} \mathrm{L}^{-1} \mathrm{NaCl}$ solution at $1.2 \mathrm{~V}$; (b) regeneration curve of the MMC-A electrodes in a $80 \mathrm{mg} \mathrm{L}^{-1} \mathrm{NaCl}$ solution at $1.2 \mathrm{~V}$. calculated to be 0.66 and 0.35 , indicating the MMC-A electrodes are more energy-saving, which attributes to that the increased micro- and mesopores are beneficial to the formation of the EDL. ${ }^{8,76}$ The charge efficiency is always lower than the theoretical value of 1 , which is mainly because of the following three reasons: (i) when we prepare the electrodes, the binder with poor conductivity such as PTFE is always used, which would increase the resistance of the electrodes; (ii) the adhesion between the carbon material and graphene paper is not very closely inevitably, which would also consume a part of charge; (iii) during the deionization process, the adsorbed ions would repel each other, which also decreases the charge utilization. ${ }^{\mathbf{8}, 77}$

To study the regeneration behavior of the MMC-A electrodes, reiterative salt adsorption-desorption experiments were conducted in a $\sim 80 \mathrm{mg} \mathrm{L}^{-1} \mathrm{NaCl}$ solution through applying charge voltage of $1.2 \mathrm{~V}$ and discharge voltage of $0 \mathrm{~V}$. As shown in Fig. 9b, when MMC-A electrodes were charged, the conductivity decreases immediately. Once the voltage is removed, the conductivity increases back to the original value rapidly. In addition, during over 10 regeneration process, the SAC of the MMC-A electrodes almost has no clear declination. In addition, the MMC-A electrodes also present a good regeneration performance in a $150 \mathrm{mg} \mathrm{\textrm {L } ^ { - 1 }} \mathrm{NaCl}$ solution (Fig. S8†). These results reveal that the MMC-A electrodes have a good regeneration behavior and stability, which further demonstrates that the MMC-A is a promising FTDC electrode material.

\section{Conclusions}

The micro/mesoporous carbon sheets with high specific surface area was successfully prepared using watermelon peels as carbon source through an activation method and originally developed as highly efficient electrodes for flow-through deionization capacitors to remove $\mathrm{NaCl}$ from saltwater solutions. The carbon source is low-cost and the preparation process is very simple, effective and environmentally-friendly. The MMC-A electrode exhibits a superior wettability and good electrochemical performance. The MMC-A electrodes also possess a high deionization capacity, fast deionization rate and good regeneration behavior. Considering these above factors, the MMC-A fairly possess good deionization performance for potential application in the flow-through deionization capacitors. We also hope that the as-prepared MMC-A can be applied to other areas such as supercapacitors, lithium ion batteries, adsorption and others.

\section{Acknowledgements}

The work was supported by the National Natural Science Foundation of China (U1462110). We also appreciate the Analysis and Test Center of SHU for the sample measurements.

\section{References}

1 M. A. Shannon, P. W. Bohn, M. Elimelech, J. G. Georgiadis, B. J. Marinas and A. M. Mayes, Nature, 2008, 452, 301-310. 
2 T. Humplik, J. Lee, S. C. O'Hern, B. A. Fellman, M. A. Baig, S. F. Hassan, M. A. Atieh, F. Rahman, T. Laoui, R. Karnik and E. N. Wang, Nanotechnology, 2011, 22, 292001.

3 H. Yin, S. Zhao, J. Wan, H. Tang, L. Chang, L. He, H. Zhao, Y. Gao and Z. Tang, Adv. Mater., 2013, 25, 6270-6276.

4 S. Porada, L. Borchardt, M. Oschatz, M. Bryjak, J. S. Atchison, K. J. Keesman, S. Kaskel, P. M. Biesheuvel and V. Presser, Energy Environ. Sci., 2013, 6, 3700-3712.

5 T. J. Welgemoed and C. F. Schutte, Desalination, 2005, 183, 327-340.

6 M. A. Anderson, A. L. Cudero and J. Palma, Electrochim. Acta, 2010, 55, 3845-3856.

7 S. Porada, R. Zhao, A. van der Wal, V. Presser and P. M. Biesheuvel, Prog. Mater. Sci., 2013, 58, 1388-1442.

8 M. E. Suss, S. Porada, X. Sun, P. M. Biesheuvel, J. Yoon and V. Presser, Energy Environ. Sci., 2015, 8, 2296-2319.

9 Y. Liu, C. Nie, X. Liu, X. Xu, Z. Sun and L. Pan, RSC Adv., 2015, 5, 15205-15225.

10 M.-W. Ryoo and G. Seo, Water Res., 2003, 37, 1527-1534.

11 J.-H. Choi, Sep. Purif. Technol., 2010, 70, 362-366.

12 T. Kim and J. Yoon, J. Electroanal. Chem., 2013, 704, 169-174.

13 H.-H. Jung, S.-W. Hwang, S.-H. Hyun, K.-H. Lee and G.-T. Kim, Desalination, 2007, 216, 377-385.

14 P. Xu, J. E. Drewes, D. Heil and G. Wang, Water Res., 2008, 42, 2605-2617.

15 M. C. Zafra, P. Lavela, G. Rasines, C. Macías, J. L. Tirado and C. O. Ania, Electrochim. Acta, 2014, 135, 208-216.

16 X. Xu, Z. Sun, D. H. Chua and L. Pan, Sci. Rep., 2015, 5, 11225.

17 B. Jia and L. Zou, Carbon, 2012, 50, 2315-2321.

18 L. Wang, M. Wang, Z.-H. Huang, T. Cui, X. Gui, F. Kang, K. Wang and D. Wu, J. Mater. Chem., 2011, 21, 18295-18299.

19 M. A. Tofighy and T. Mohammadi, Desalination, 2010, 258, 182-186.

20 L. Zou, L. Li, H. Song and G. Morris, Water Res., 2008, 42, 2340-2348.

21 C. Tsouris, R. Mayes, J. Kiggans, K. Sharma, S. Yiacoumi, D. DePaoli and S. Dai, Environ. Sci. Technol., 2011, 45, 10243-10249.

22 A. G. El-Deen, N. A. M. Barakat, K. A. Khalil and H. Y. Kim, J. Mater. Chem. A, 2013, 1, 11001-11010.

23 G. Wang, C. Pan, L. Wang, Q. Dong, C. Yu, Z. Zhao and J. Qiu, Electrochim. Acta, 2012, 69, 65-70.

24 A. G. El-Deen, N. A. M. Barakat, K. A. Khalil and H. Y. Kim, New J. Chem., 2014, 38, 198-205.

25 H. Li, L. Pan, C. Nie, Y. Liu and Z. Sun, J. Mater. Chem., 2012, 22, 15556-15561.

26 Q. Dong, G. Wang, B. Qian, C. Hu, Y. Wang and J. Qiu, Electrochim. Acta, 2014, 137, 388-394.

27 Y. Wimalasiri and L. Zou, Carbon, 2013, 59, 464-471.

28 H. Li, S. Liang, J. Li and L. He, J. Mater. Chem. A, 2013, 1, 6335-6341.

29 C. Long, L. Jiang, X. Wu, Y. Jiang, D. Yang, C. Wang, T. Wei and Z. Fan, Carbon, 2015, 93, 412-420.

30 K. Xia, Q. Gao, J. Jiang and J. Hu, Carbon, 2008, 46, 17181726.
31 J. Deng, T. Xiong, F. Xu, M. Li, C. Han, Y. Gong, H. Wang and Y. Wang, Green Chem., 2015, 17, 4053-4060.

32 M. Rose, Y. Korenblit, E. Kockrick, L. Borchardt, M. Oschatz, S. Kaskel and G. Yushin, Small, 2011, 7, 1108-1117.

33 X. Deng, B. Zhao, L. Zhu and Z. Shao, Carbon, 2015, 93, 4858.

34 L. Qie, W. Chen, H. Xu, X. Xiong, Y. Jiang, F. Zou, X. Hu, Y. Xin, Z. Zhang and Y. Huang, Energy Environ. Sci., 2013, 6, 2497-2504.

35 R. T. Mayes, C. Tsouris, J. O. Kiggans Jr, S. M. Mahurin, D. W. DePaoli and S. Dai, J. Mater. Chem., 2010, 20, 86748678.

36 G. Wang, Q. Dong, Z. Ling, C. Pan, C. Yu and J. Qiu, J. Mater. Chem., 2012, 22, 21819-21823.

37 X. Wen, D. Zhang, L. Shi, T. Yan, H. Wang and J. Zhang, J. Mater. Chem., 2012, 22, 23835-23844.

38 B. Li, D. Geng, X. S. Lee, X. Ge, J. Chai, Z. Wang, J. Zhang, Z. Liu, T. S. Hor and Y. Zong, Chem. Commun., 2015, 51, 8841-8844.

39 Z. Li, W. Lv, C. Zhang, B. Li, F. Kang and Q.-H. Yang, Carbon, 2015, 92, 11-14.

40 R. Wang, P. Wang, X. Yan, J. Lang, C. Peng and Q. Xue, ACS Appl. Mater. Interfaces, 2012, 4, 5800-5806.

41 Y. Lv, L. Gan, M. Liu, W. Xiong, Z. Xu, D. Zhu and D. S. Wright, J. Power Sources, 2012, 209, 152-157.

42 A. Elmouwahidi, Z. Zapata-Benabithe, F. Carrasco-Marin and C. Moreno-Castilla, Bioresour. Technol., 2012, 111, 185190.

43 X. Li, W. Xing, S. Zhuo, J. Zhou, F. Li, S. Z. Qiao and G. Q. Lu, Bioresour. Technol., 2011, 102, 1118-1123.

44 H. Zhu, X. Wang, F. Yang and X. Yang, Adv. Mater., 2011, 23, 2745-2748.

45 E. Raymundo-Piñero, F. Leroux and F. Béguin, Adv. Mater., 2006, 18, 1877-1882.

46 E. Raymundo-Piñero, M. Cadek and F. Béguin, Adv. Funct. Mater., 2009, 19, 1032-1039.

47 D. Kang, Q. Liu, J. Gu, Y. Su, W. Zhang and D. Zhang, ACS Nano, 2015, 9, 11225-11233.

48 T. E. Rufford, D. Hulicova-Jurcakova, Z. Zhu and G. Q. Lu, Electrochem. Commun., 2008, 10, 1594-1597.

49 J. Zhou, Z. Sheng, H. Han, M. Zou and C. Li, Mater. Lett., 2012, 66, 222-224.

$50 \mathrm{X} . \mathrm{Wu}, \mathrm{T}$. Wen, H. Guo, S. Yang, X. Wang and A. Xu, ACS Nano, 2013, 7, 3589-3597.

51 H. Lei, T. Yan, H. Wang, L. Shi, J. Zhang and D. Zhang, J. Mater. Chem. A, 2015, 3, 5934-5941.

52 H. Wang, D. Zhang, T. Yan, X. Wen, J. Zhang, L. Shi and Q. Zhong, J. Mater. Chem. A, 2013, 1, 11778-11789.

53 L. Chang, J. Li, X. Duan and W. Liu, Electrochim. Acta, 2015, 176, 956-964.

54 Y. Liu, L. Pan, T. Chen, X. Xu, T. Lu, Z. Sun and D. H. C. Chua, Electrochim. Acta, 2015, 151, 489-496.

55 M. Thommes, K. Kaneko, A. V. Neimark, J. P. Olivier, F. Rodriguez-Reinoso, J. Rouquerol and K. S. W. Sing, Pure Appl. Chem., 2015, 87, 1051-1069.

56 K. Y. Foo and B. H. Hameed, Bioresour. Technol., 2011, 102, 9814-9817. 
57 K. Y. Foo and B. H. Hameed, Microporous Mesoporous Mater., 2012, 148, 191-195.

58 X.-J. Jin, Z.-M. Yu and Y. Wu, Cellul. Chem. Technol., 2012, 46, 79-85.

59 S. Zhao, T. Yan, H. Wang, J. Zhang, L. Shi and D. Zhang, ACS Appl. Mater. Interfaces, 2016, 8, 18027-18035.

60 J. Zhang, X. Zhang, Y. Zhou, S. Guo, K. Wang, Z. Liang and Q. Xu, ACS Sustainable Chem. Eng., 2014, 2, 1525-1533.

61 W. Luo, B. Wang, C. G. Heron, M. J. Allen, J. Morre, C. S. Maier, W. F. Stickle and X. Ji, Nano Lett., 2014, 14, 2225-2229.

62 D. Wang, C. Li, J. Guo and T. Li, Desalin. Water Treat., 2015, 1-7.

63 B. Xu, F. Wu, R. Chen, G. Cao, S. Chen, G. Wang and Y. Yang, J. Power Sources, 2006, 158, 773-778.

64 D. Zhang, T. Yan, L. Shi, Z. Peng, X. Wen and J. Zhang, J. Mater. Chem., 2012, 22, 14696-14704.

65 M. Zhong, Y. Song, Y. Li, C. Ma, X. Zhai, J. Shi, Q. Guo and L. Liu, J. Power Sources, 2012, 217, 6-12.

66 K. T. Cho, S. B. Lee and J. W. Lee, J. Phys. Chem. C, 2014, 118, 9357-9367.

67 K.-B. Li, D.-W. Shi, Z.-Y. Cai, G.-L. Zhang, Q.-A. Huang, D. Liu and C.-P. Yang, Electrochim. Acta, 2015, 174, 596-600.
68 P. F. Fulvio, R. T. Mayes, X. Wang, S. M. Mahurin, J. C. Bauer, V. Presser, J. McDonough, Y. Gogotsi and S. Dai, Adv. Funct. Mater., 2011, 21, 2208-2215.

69 J. Yan, T. Wei, B. Shao, F. Ma, Z. Fan, M. Zhang, C. Zheng, Y. Shang, W. Qian and F. Wei, Carbon, 2010, 48, 1731-1737.

70 L. Mao, H. S. O. Chan and J. Wu, RSC Adv., 2012, 2, 1061010617.

71 A. Bello, F. Barzegar, D. Momodu, J. Dangbegnon, F. Taghizadeh and N. Manyala, Electrochim. Acta, 2015, 151, 386-392.

72 J. Chang, M. Jin, F. Yao, T. H. Kim, V. T. Le, H. Yue, F. Gunes, B. Li, A. Ghosh, S. Xie and Y. H. Lee, Adv. Funct. Mater., 2013, 23, 5074-5083.

73 T. Kim and J. Yoon, RSC Adv., 2015, 5, 1456-1461.

74 Y. Wimalasiri, M. Mossad and L. Zou, Desalination, 2015, 357, 178-188.

75 R. Zhao, P. M. Biesheuvel, H. Miedema, H. Bruning and A. van der Wal, J. Phys. Chem. Lett., 2010, 1, 205-210.

76 P. M. Biesheuvel, S. Porada, M. Levi and M. Z. Bazant, J. Solid State Electrochem., 2014, 18, 1365-1376.

77 X. Xu, L. Pan, Y. Liu, T. Lu, Z. Sun and D. H. Chua, Sci. Rep., 2015, 5, 8458. 